\title{
APLICACIÓN DE UN ÍNDICE DE CALIDAD AMBIENTAL: RECURSOS RECREATIVOS Y PROBLEMAS AMBIENTALES \\ EN LOS DEPARTAMENTOS DEL NOROESTE DE LA REPÚBLICA ARGENTINA
}

\author{
APPLICATION OF AN ENVIRONMENTAL QUALITY INDEX: RECREATION \\ RESOURCES AND ENVIRONMENTAL ISSUES IN MUNICIPALITIES OF \\ NORTHWEST ARGENTINA
}

\author{
Juan Pablo Celemin \\ jpcelemin@conicet.gov.ar \\ Guillermo Angel Velazquez \\ gvelaz@fch.unicen.edu.ar
}

Resumen

La dimensión ambiental es uno de los componentes fundamentales al momento de estudiar la distribución espacial de índices de calidad de vida de la población. Estos son cada vez más necesarios para establecer con precisión los aspectos vinculados con las condiciones de vida de la población en diferentes escalas. En la Argentina, sin embargo, existe cierta demora en la elaboración de índices ambientales con respecto a la de otros asociados con variables sociales y económicas debido a que son obtenidos en escalas temporales y especiales que dificultan su complementariedad. Para comenzar a suplir esta carencia este trabajo plantea la elaboración de un índice de calidad ambiental para los departamentos que constituyen las provincias del Noroeste de la República Argentina. Para su implementación recurre a veintitrés variables agrupadas en tres grandes dimensiones denominadas a) recursos recreativos de base natural; b) recursos socialmente construidos y c) problemas ambientales que fueron valoradas a partir de la conjunción de puntuaciones subjetivas y objetivas. La configuración espacial permite destacar como las capitales provinciales se benefician con la mayor presencia de recursos recreativos socialmente construidos, a la vez que son perjudicadas por los problemas ambientales. Estos también están presentes en zonas con menor componente demográfico donde predominan las actividades mineras y agrícolas intensivas. Por su parte, los recursos de base natural aumentan hacia el oeste de la región debido al atractivo que tienen las áreas montañosas en detrimento de la llanura que predomina en el este del área de estudio.

Palabras clave: índice de calidad ambiental, recursos recreativos de base natural y socialmente construidos, problemas ambientales, Noroeste de la República Argentina 


\section{APLICAÇÃO DE UM ÍNDICE DE QUALIDADE AMBIENTAL: RECURSOS RECREATIVOS E PROBLEMAS AMBIENTAIS EM MUNICÍPIOS DA NOROESTE DA REPÚBLICA ARGENTINA}

\section{Resumo}

A dimensão ambiental é um componente essencial quando se estuda a distribuição espacial dos índices de qualidade de vida da população. Estes são cada vez mais necessário para estabelecer precisamente os aspectos relacionados às condições de vida da população em diferentes escalas. Na Argentina, porém, há algum atraso no desenvolvimento de índices ambientais em relação a outras variáveis associadas com o social e econômico, porque eles são obtidos em escalas espacial e temporal que impedem a sua complementaridade. Para começar a preencher esta lacuna este trabalho apresenta o desenvolvimento de um índice de qualidade ambiental para os departamentos que constituem as províncias do noroeste da Argentina. O índice compõe-se de uma combinação de 23 variáveis agrupadas em três grandes dimensões chamados a) recriação baseada em recursos naturais, b) recursos socialmente construídos e c) problemas ambientais que foram avaliados a partir de uma combinação de pontuação subjetiva e objetiva. A configuração espacial nos permite destacar as capitais provinciais e beneficiar do aumento da presença de recursos de lazer socialmente construídos, enquanto eles são prejudicados por problemas ambientais. Estes também estão presentes em áreas com menor população dominada por atividades agrícolas intensas e de mineração. Por sua parte, há um aumento de recursos da base naturais para o oeste da região, devido ao apelo das zonas de montanha, em detrimento da planície que domina a leste da área de estudo

Palavras-chave: índice de qualidade ambiental, recursos recreativos de base natural, recursos socialmente construídos, problemas ambientais, noroeste da Argentina

\section{Introducción}

Una de las principales características de los índices es que según su grado de agregación de la información puede ser utilizado con distintas finalidades: en el ámbito académico sirve para realizar análisis detallado de sus componentes y distribución espacial, para que los agentes con capacidad de decisión elaboren mejores estrategias para incrementar el bienestar de la población y por último es de utilidad para informar al público en general acerca del estado en cuestión (Tanguay et al., 2010).

En la actualidad existe una demanda de mayor y mejor información ambiental, en especial por algunos sectores sociales con creciente interés por los aspectos ambientales del desarrollo y el bienestar social. A medida que mejora su situación 
socioeconómica, surgen nuevos intereses y preocupaciones, tal es el caso del ambiente y la ecología.

La información ambiental presenta dos limitaciones: la primera es compartida con los datos sociales y económicos y refiere a la agregación y simplificación de la información, con el objetivo de la divulgación científica, reduce el poder analítico de los resultados pero, a su vez, hace visibles a todos los estratos de la sociedad gran cantidad de datos resumidos. En segundo lugar están las restricciones a su accesibilidad, disponibilidad y confiabilidad, en particular aquellos que describen características a escala urbana o municipal. Mientras que diferentes organismos nacionales, provinciales y municipales elaboran periódicamente indicadores para conocer el contexto socioeconómico de sus correspondientes jurisdicciones, las variables ambientales poseen escalas de análisis espaciales y temporales diferenciales. Esta característica obstaculiza el trabajo concordar la información ambiental con la socioeconómica. Por lo tanto, un análisis como el presente deba buscar un compromiso entre escala de análisis, disponibilidad de información y recursos existentes para poder cumplimentar sus objetivos.

La elaboración y seguimiento del índice puede realizarse bajo dos enfoques, objetivo y subjetivo. Mientras que el primero se basa en información de origen secundario, el último considera a las percepciones que proporcionan una visión más completa que las observaciones frías y "objetivas" proporcionadas por los datos. Siempre que se utilicen adecuadamente estos enfoques, y se comprendan los alcances y limitaciones de cada uno, pueden ser utilizados complementariamente (Sterimberg, et al., 2004).

En este contexto, el objetivo de este trabajo es elaborar y mostrar la distribución espacial de un Índice de Calidad Ambiental (ICA) aplicado a los departamentos que conforman el Noroeste de la República Argentina considerando a los recursos recreativos, tanto de base natural como socialmente construidos y a los costos ambientales, destacando sus disparidades en el territorio en cuestión. Consiguientemente, el ICA se propone, por un lado, dimensionar la magnitud de algunos problemas ambientales que afectan al bienestar de la población y por otro, en el caso de elementos subjetivos como la valoración de los recursos escénicos o de los elementos de esparcimiento, una cuantificación de la percepción. 
El índice de calidad ambiental propuesto considera no solo a las habituales variables vinculadas con el medio físico-natural sino también al espacio construido ya que es en él donde la población desarrolla su quehacer cotidiano. Como afirma Santos (1996) es aquí donde la geografía puede brindar una contribución importante para otras disciplinas, porque el cotidiano pasa a ser definido por el lugar, esto es, la manera como la gente vive su cotidiano y se vincula territorialmente en una ciudad determinada.

Por tanto, se hace necesario recurrir a una concepción amplia del ambiente: es decir el conjunto de las diferentes relaciones establecidas entre la sociedad y el medio físico, construido o hecho artificial, que tiene lugar en un espacio territorial acotado. Implica considerar simultáneamente usos de la tierra yuxtapuestos entre sí, multiplicidad de procesos y actores productores y reproductores de ese medio, variedad de significados y símbolos culturales (Herzer y Gurevich, 2006) que alcanzan su máxima expresión en la ciudades y su entorno, ya que producen un medio ambiente que le es propio, cuya principal característica es estar "socialmente construido", lo que lo diferencia fundamentalmente del medio ambiente natural estudiado por la ecología (Metzger 2006). Consiguientemente, el índice también incluye las variables asociadas con la calidad desde una perspectiva más amplia como pueden ser la seguridad y las amenidades urbanas a la vez que intenta diferenciarse de los índices elaborados por economistas que recurren a métodos hedónicos o de valoración continente. La crítica a ese tipo de procedimientos es su reduccionismo economicista dado que todos los indicadores considerados tienen que estar asociados con el valor monetario. Rogerson (1999) y McCann (2004) los cuestionan ya que de esta manera la ciudad o el municipio es vista exclusivamente como un bien que es parte de un proceso de competición interurbana por la atracción del capital y de recursos humanos calificados.

En tal sentido, Araña et al. (2003) sostiene que el ambiente que debe ser gestionado desde organismos públicos que no tengan en cuenta únicamente al mercado como elemento de asignación de los bienes ambientales, impidiendo que la mayoría de la población sufra una calidad de vida por debajo de lo deseable.

La calidad ambiental es un concepto complejo tratado por multiplicidad de disciplinas que carece de una definición precisa dado que las producciones científicas, en general, la tratan de manera implícita y el lector debe analizar a los indicadores utilizados para determinar a que está refiriendo. Suele estar vinculada a otro tipo de 
nociones -igualmente de difusas y complejas- tales como calidad de vida, sostenibilidad y habitabilidad, (van Kamp, et al., 2003). Un aporte abarcativo es el Luengo (1998) que entiende por calidad ambiental a las condiciones óptimas que rigen el comportamiento del espacio habitable en términos de confort asociados a lo ecológico, biológico, económico-productivo, socio-cultural, tipológico, tecnológico y estético en sus dimensiones espaciales. Así, la calidad ambiental es, por extensión, producto de la interacción de estas variables para la conformación de un hábitat saludable, confortable y capaz de satisfacer los requerimientos básicos de sostenibilidad de la vida humana individual y en interacción social dentro del medio urbano. Dada la versatilidad de la noción en cuestión, Escobar (2006) indica que la calidad ambiental puede ser concebida como un componente más del desarrollo sostenible urbano, junto con las condiciones económicas y sociales.

\section{Región del Noroeste Argentino: breve caracterización regional}

Del mosaico de regiones que conforman la Argentina, la Región del Noroeste Argentino (NOA), posee características contradictorias y un grado de desarrollo relativamente bajo. Históricamente la actividad económica que le generó "viabilidad" fue la agroindustria azucarera, que se expandió en forma coincidente con el modelo agro-exportador pampeano (1860-1930). Posteriormente, otra serie de actividades (poroto y talleres ferroviarios en los sesenta; acero y petróleo en los setenta y ochenta; soja y citricultura desde los noventa) han permitido una inserción regional de sus grupos hegemónicos en el contexto nacional e internacional.

En términos generales, para el Sistema Estadístico Nacional, la Región del NOA abarca íntegramente las provincias de Tucumán, Salta, Jujuy, Catamarca, La Rioja y Santiago del Estero. Siguiendo a Bolsi, et al. (2008), estas seis provincias cubren más de 550.000 kilómetros cuadrados, es decir, el 20 por ciento de la superficie continental del país. Este amplísimo ámbito subtropical está conformado por dos grandes sectores: el occidental, donde la montaña es el hecho dominante, y el oriental -más extensoocupado en su mayor parte por la llanura. ${ }^{1}$ Los efectos de la distancia a los océanos Pacífico y Atlántico, de las variaciones altitudinales, de la circulación general de la

1. Se entiende que el papel de la naturaleza en la territorialización se expresa a través de tres dimensiones: la restrictiva, definida por la existencia de sectores con grandes obstáculos para el desarrollo de la vida humana; la relativa, asociada con su significado cambiante según los cambios en las prácticas materiales y la regresiva, vinculada con los efectos de la explotación indiscriminada.

Geo UERJ - Ano 14, no. 23, v. 1, $1^{\circ}$ semestre de 2012 p. 53-76

ISSN: 1415-7543 E-ISSN: 1981-9021

http://www.e-publicacoes.uerj.br/index.php/geouerj 
atmósfera, de la orientación de los encadenamientos montañosos, de los procesos tectónicos y geomorfológicos, etcétera, se hacen sentir en la riquísima y compleja red de paisajes naturales que caracterizan al NOA. Numerosas contribuciones científicas han dado cuenta de sus rasgos generales y de sus detalles, pero no se puede dejar de puntualizar que la naturaleza, en esta porción del país, no escatima los extremos: cuenta con cadenas montañosas ubicadas entre los más elevadas de las Américas; en pocas decenas de kilómetros pueden salvarse desniveles de 6.000 metros, de más de 2.000 milímetros de lluvia y trasladarse desde las nieves permanentes hasta los tórridos ámbitos santiagueños; es atravesada por una riquísima red fluvial; su sector oriental está muy próximo al polo de calor sudamericano; contiene amplia superficie boscosa, a la vez que registra la variedad vegetal más rica del país; posee, en fin, las amplitudes térmicas más pronunciadas de la Argentina. La variación es la norma.

En efecto, y siguiendo a Difrieri (1958), desde el punto de vista natural las provincias que componen el Noroeste Argentino (Mapa 1) pueden dividirse en 5 grandes sub-regiones:

1) En el borde noroccidental se encuentra la Puna, inmenso altiplano rodeado de montañas cuyas altitudes superan los 6000 metros. Esos caracteres definen un ambiente dominado por los extremos: escasas precipitaciones, fuertes vientos, suelos pobres. La presencia humana ha sido muy débil y se ha limitado, en un contexto de precarias condiciones de existencia, a aquellos sectores en donde la disponibilidad de agua y el clima así lo han permitido.

2) Hacia el este de la Puna hay una serie de encadenamientos montañosos de orientación meridiana -las denominadas Sierras Subandinas- separados entre si por valles de dimensiones variables que por sus condiciones naturales más favorables han facilitado la instalación humana.

3) Más hacia el este, los bloques que conforman estas sierras se sumergen en los sedimentos aluviales del Chaco Oriental, que conforman una extensa llanura con pendiente general, poco pronunciada, que sigue un rumbo noroeste-sudeste. La sequedad es allí la nota característica y lentamente los cursos de agua que bajan de las sierras, languidecen a medida que avanzan.

4) Por el sur, desde Tucumán hasta La Rioja, se encuentran las Sierras Pampeanas y una profusión de bolsones y semi-bolsones. Las sierras constituyen una serie de bloques

Geo UERJ - Ano 14, no. 23, v. 1, $1^{\circ}$ semestre de 2012 p. 53-76

ISSN: 1415-7543 E-ISSN: 1981-9021

http://www.e-publicacoes.uerj.br/index.php/geouerj 
antiguos rejuvenecidos en el Terciario, mientras que los bolsones son las fosas rellenadas por los sedimentos provenientes de la erosión de los bloques más elevados. Han sido precisamente estos valles tectónicos donde las condiciones naturales ofrecen menores restricciones, las áreas privilegiadas para la instalación humana y los cultivos.

5) Hacia el oeste de las Sierras Pampeanas, tenemos la Precordillera. Esta elevación, surgida también durante la orogenia terciaria, se encuentra marcada por una profusión de valles longitudinales que la separan de la cordillera. El agua es allí también un elemento esquivo; los cursos de agua, importantes en muchos casos, son todos alóctonos y se aprovechan profusamente a lo largo de sus cursos para las actividades humanas (Difrieri, 1958).

Estos paisajes, muy diferentes unos de otros, han sido ocupados de manera diferencial en el tiempo por distintas sociedades. Los caracteres de esas diferentes sociedades y su interacción con el ambiente, fueron los que definieron, a lo largo del tiempo distintas formas de ocupación del espacio y los que le otorgaron su fisonomía. De todos ellos, han sido los valles -tanto fluviales como tectónicos- y los piedemontes de las sierras los espacios preferidos para la ocupación humana.

Pero a pesar de su extensión -y de sus cambiantes condiciones naturales- sólo viven en el NOA poco más de 4.400.000 habitantes, o sea en torno al 12 por ciento del total de la población argentina. De ese conjunto, más del 78 por ciento vive en localidades urbanas, incluidas en un sistema caracterizado por la alta concentración de habitantes en las capitales provinciales, donde reside casi la mitad de la población. ${ }^{2}$

2. Para ampliación de estos conceptos, recomendamos el libro de Bolsi y Paolasso (2009).

Geo UERJ - Ano 14, no. 23, v. 1, $1^{\circ}$ semestre de 2012 p. 53-76

ISSN: 1415-7543 E-ISSN: 1981-9021

http://www.e-publicacoes.uerj.br/index.php/geouerj 

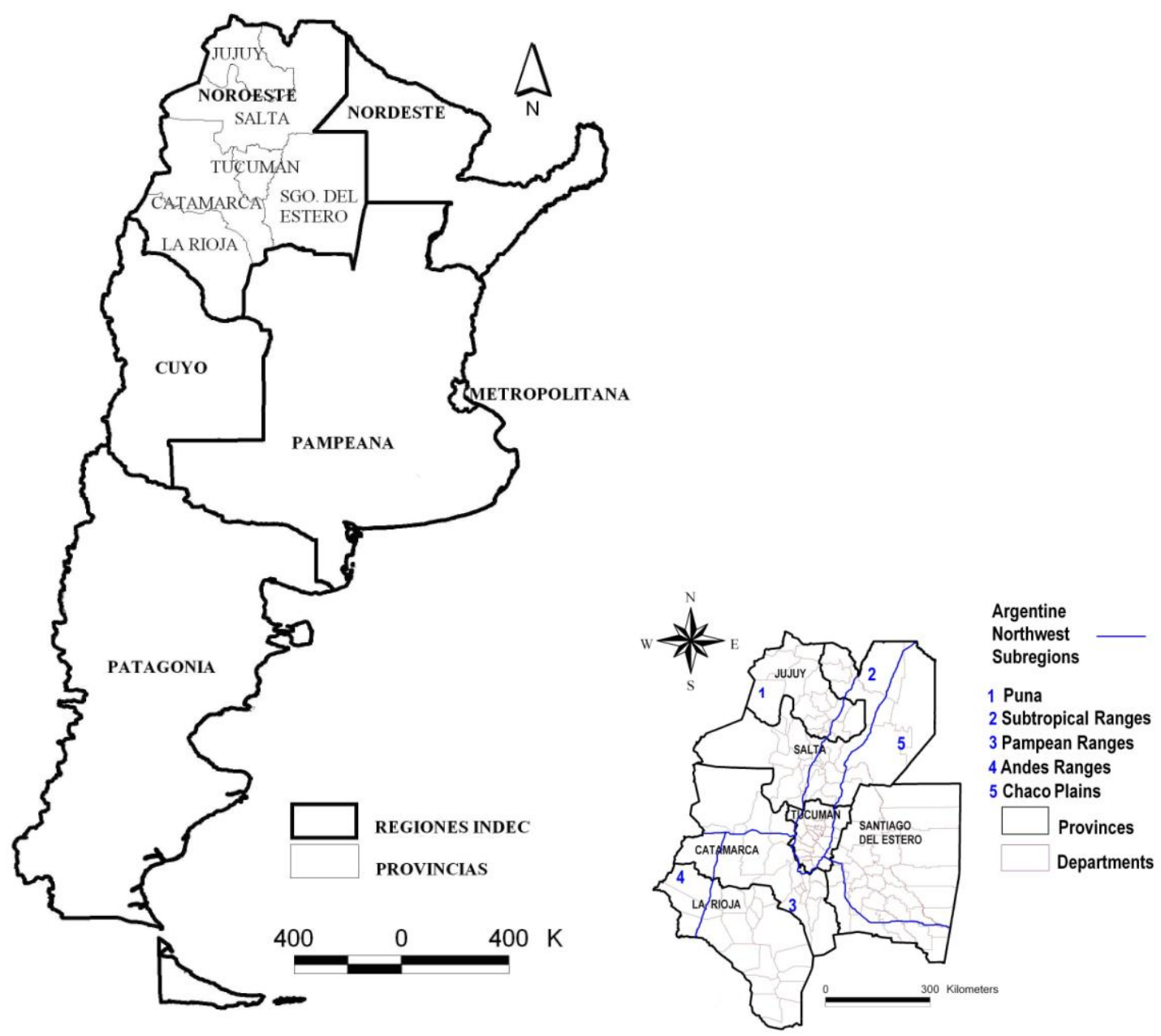

Mapa. 1. Regiones Argentinas. Ubicación del NOA y subregiones.

Fuente: elaboración personal sobre la base de cartografía oficial del IGN y cartografía censal del INDEC

\section{Metodología}

La metodología de construcción de un índice presenta gran complejidad, dado que deben seleccionarse variables representativas de la situación que se pretende mostrar. Dichas variables, no son directamente extrapolables a otros espacios, ya que cada uno de ellos posee especificidades y dinámicas que le son propias. Por tanto, esta característica hace que la elaboración varíe según diferentes ámbitos geográficos. Tanto en la forma de agrupar las variables, como en su ponderación, existe un componente subjetivo. Se trata, entonces, de un procedimiento relativamente arbitrario en el que ningún método puede justificarse con totalidad porque una variable posee mayor ponderación que otra (Tanguay et al., 2010). Además, la pertenencia de las variables a una categoría superior no es definitiva ya que alguna puede pertenecer a más de una. 
Este tipo de agrupación es una forma de organizar mejor la información de acuerdo con la similitud existente entre las variables y la finalidad del índice.

Para los municipios de la República Argentina se han elaborado índices de calidad de vida en diferentes escalas que contemplan la dimensión ambiental y que fueron ponderados tanto con procedimientos exclusivamente matemáticos Boroni et al. (2005); Cepeda et al. (2004); Marinelli et al. (1999) como directos (Autor 2008) con resultados espacialmente similares. Por otra parte Ramírez (2004) y Valpreda (2007) recurren a otros métodos para evaluar variables, tal es el caso del conocido como Jerarquías Analíticas, basado en comparaciones de pares de criterios (variables). Por último, Autor y Autor (2011) elaboraron un índice de calidad ambiental para los departamentos de la Región Pampeana Argentina combinado ponderaciones subjetivas y objetivas, propuesta que retomamos en este trabajo.

Sobre la base de lo enunciado con anterioridad, el ICA se compuso de veintitrés componentes centrales (Tabla 1), desagregados en dos grandes dimensiones: recursos recreativos y problemas ambientales.

Tabla 1. Indicadores del Indice de Calidad Ambiental

\begin{tabular}{|c|c|c|c|}
\hline \multicolumn{4}{|c|}{ INDICE DE CALIDAD AMBIENTAL PARA LA REGIÓN DEL NOA } \\
\hline \multirow{8}{*}{$\begin{array}{c}\text { Recursos } \\
\text { recreativos } \\
\text { de base } \\
\text { natural } \\
\text { (ponderación } \\
30 \% \text { ) }\end{array}$} & $\begin{array}{c}\text { Variable (puntajes } \\
\text { Omega: mín 0, máx 10) }\end{array}$ & $\begin{array}{c}\text { Criterio de } \\
\text { Evaluación }\end{array}$ & Fuente \\
\hline & Playas & Subjetivo & $\begin{array}{l}\text { Información } \\
\text { Municipal/terreno/imágenes } \\
\text { satelitales }\end{array}$ \\
\hline & $\begin{array}{l}\text { Balnearios a orillas de ríos, } \\
\text { lagos, lagunas o diques }\end{array}$ & Subjetivo & $\begin{array}{l}\text { Información } \\
\text { Municipal/terreno/imágenes } \\
\text { satelitales }\end{array}$ \\
\hline & Centros termales & Subjetivo & $\begin{array}{l}\text { Información } \\
\text { Municipal/terreno/imágenes } \\
\text { satelitales }\end{array}$ \\
\hline & $\begin{array}{l}\text { Nieve/hielo (posibilidad de } \\
\text { actividades recreativas } \\
\text { invernales) }\end{array}$ & Subjetivo & $\begin{array}{l}\text { Información } \\
\text { Municipal/terreno/imágenes } \\
\text { satelitales }\end{array}$ \\
\hline & Relieve & Subjetivo & $\begin{array}{l}\text { Información } \\
\text { Municipal/terreno/imágenes } \\
\text { satelitales }\end{array}$ \\
\hline & Espejos y cursos de agua & Subjetivo & $\begin{array}{l}\text { Información } \\
\text { Municipal/terreno/imágenes } \\
\text { satelitales }\end{array}$ \\
\hline & Parques y espacios verdes & Subjetivo & $\begin{array}{l}\text { Información } \\
\text { Municipal/terreno/imágenes }\end{array}$ \\
\hline
\end{tabular}

Geo UERJ - Ano 14, nº. 23, v. 1, $1^{\circ}$ semestre de 2012 p. 53-76

ISSN: 1415-7543 E-ISSN: 1981-9021

http://www.e-publicacoes.uerj.br/index.php/geouerj 


\begin{tabular}{|c|c|c|c|}
\hline & & & satelitales \\
\hline \multirow{4}{*}{$\begin{array}{c}\text { Recursos } \\
\text { recreativos } \\
\text { socialmente } \\
\text { construidos } \\
\text { (ponderación } \\
30 \% \text { ) }\end{array}$} & Estética/Patrimonio urbano & Subjetivo & Información Municipal/terreno \\
\hline & Centros culturales & Subjetivo & Información Municipal/terreno \\
\hline & $\begin{array}{l}\text { Centros comerciales y de } \\
\text { esparcimiento }\end{array}$ & Subjetivo & Información Municipal/terreno \\
\hline & Centros deportivos & Subjetivo & Información Municipal/terreno \\
\hline \multirow{12}{*}{$\begin{array}{l}\text { Problemas } \\
\text { ambientales } \\
\text { (ponderación } \\
40 \% \text { ) }\end{array}$} & $\begin{array}{l}\text { Uso de plaguicidas en } \\
\text { agricultura }\end{array}$ & Objetivo & $\begin{array}{l}\text { Defensoría del Pueblo. Atlas } \\
\text { Ambiental de la Niñez (2009) }\end{array}$ \\
\hline & $\begin{array}{l}\text { Participación de Industria y } \\
\text { minería en el PBG }\end{array}$ & Objetivo & Argentina. INDEC (2003) \\
\hline & $\begin{array}{l}\text { Contaminación/Ruido } \\
\text { /Congestionamiento }\end{array}$ & Subjetivo & $\begin{array}{l}\text { Información } \\
\text { Municipal/terreno/escala urbana }\end{array}$ \\
\hline & Localizaciones peligrosas & Subjetivo & $\begin{array}{l}\text { Información } \\
\text { Municipal/terreno/imágenes } \\
\text { satelitales }\end{array}$ \\
\hline & $\begin{array}{l}\text { Localizaciones con } \\
\text { Externalidades negativas }\end{array}$ & Subjetivo & $\begin{array}{l}\text { Información } \\
\text { Municipal/terreno/imágenes } \\
\text { satelitales }\end{array}$ \\
\hline & $\begin{array}{l}\text { Inseguridad (Tasa de } \\
\text { hechos delictivos cada } 10 . \\
000 \text { habitantes) }\end{array}$ & Objetivo & $\begin{array}{l}\text { Argentina. Dirección Nacional } \\
\text { de Política Criminal (2008) }\end{array}$ \\
\hline & $\begin{array}{l}\text { Asentamientos precarios } \\
\text { (\% de población residente } \\
\text { en villas miseria) }\end{array}$ & Objetivo & $\begin{array}{l}\text { Argentina. INDEC. Censo } \\
\text { Nacional } 2001 \text { (Información } \\
\text { Inédita, 2004) }\end{array}$ \\
\hline & $\begin{array}{l}\text { Basurales }^{3} \text { (\% de población } \\
\text { residente a menos de } 300 \\
\text { metros de un basural a } \\
\text { cielo abierto) }\end{array}$ & Objetivo & $\begin{array}{l}\text { Argentina. INDEC. Censo } \\
\text { Nacional } 2001 \text { (Información } \\
\text { Inédita, 2004) }\end{array}$ \\
\hline & Sismicidad y vulcanismo & Objetivo & $\begin{array}{l}\text { Chiozza et al. Atlas Total de la } \\
\text { Rep. Argentina (1981-1983) }\end{array}$ \\
\hline & Tornados & Objetivo & $\begin{array}{l}\text { Geosistemas. Mapas de Riesgos } \\
\text { Naturales en la Argentina } \\
\text { (1997) }\end{array}$ \\
\hline & $\begin{array}{l}\text { Porcentaje de hogares en } \\
\text { zonas inundables }\end{array}$ & Objetivo & $\begin{array}{l}\text { Argentina. INDEC. Censo } \\
\text { Nacional 2001 (Información } \\
\text { Inédita, 2004) }\end{array}$ \\
\hline & Disonfort climático ${ }^{4}$ & Objetivo & $\begin{array}{l}\text { IRAM. Clasificación } \\
\text { bioambiental de la Rep. } \\
\text { Argentina (1996) }\end{array}$ \\
\hline
\end{tabular}

\footnotetext{
${ }^{3}$ Término utilizado por en censo.

${ }^{4}$ las normas IRAM miden el confort climático (clasificación bioambiental) pero nosotros, en realidad medimos el grado de no-confort, al que denominamos disconfort.

Geo UERJ - Ano 14, nº. 23, v. 1, $1^{\circ}$ semestre de 2012 p. 53-76

ISSN: 1415-7543 E-ISSN: 1981-9021

http://www.e-publicacoes.uerj.br/index.php/geouerj
} 
Los recursos escénicos y recreativos; a su vez, pueden ser a) de base natural $(30 \%)$ o b) socialmente construidos (30\%). Como recursos de amenidad, forman parte del cotidiano e inciden en el bienestar de la población. Como afirma Santos (1996) es aquí donde la Geografía puede brindar una contribución importante para otras disciplinas sociales, porque el cotidiano pasa a ser definido por el lugar, esto es, la manera como la gente vive su cotidiano y se vincula territorialmente en determinada ciudad.

Para la valoración de los recursos recreativos de base natural partimos del supuesto de que cada lugar posee un atractivo predominante (playas, relieve, parques, espejos o cursos de agua, etc.). Según su magnitud en relación con la población residente hemos valorizado el atractivo predominante en una escala de 0 a 10 puntos. $\mathrm{Si}$ además de este elemento distintivo existiesen otros, éstos se contabilizan asignando puntajes adicionales de acuerdo con su calidad (siempre respecto de la población residente).

Para la valoración de los recursos recreativos socialmente construidos se parte del supuesto de que cada lugar suele poseer varios atributos, que también pueden ser valorizados en relación con la población residente. En este caso, al tratarse de recursos "reproducibles", se califica a cada uno de ellos de 0 a 10 y se les asigna un puntaje estableciendo el promedio respectivo.

La tercera dimensión del ICA la constituyen los problemas (costos) ambientales entendidos como los datos diversos que tienden a configurar la entidad y magnitud del problema ambiental, caracterizando y midiendo su expresión, alcance geográfico, duración temporal, naturaleza e intensidad de afectación a componentes diversos del sistema ambiental (Fernández 2000). Sin información no hay manera objetiva de construir un escenario de aprehensión científica de los problemas ni su grado de afectación ambiental.

La dimensión incluye doce posibles problemas que pueden presentarse con diferente magnitud y que afectan las condiciones de vida de la población. Como no son excluyentes entre sí, para considerar el grado de afectación se suman las incidencias estandarizadas (puntajes omega) de cada uno para establecer el respectivo subtotal. 
La mayoría de los problemas ambientales pueden ser conocidos de manera objetiva a partir de la información provista por distintos organismos municipales, provinciales y nacionales.

Como se puede observar en el cuadro 1, el ICA resulta de la combinación ponderada de:
A) $30 \%$ recursos recreativos de base natural
B) $30 \%$ recursos recreativos socialmente construidos
C) $40 \%$ problemas ambientales

Por lo que:

$$
\text { ICA: }((3 * \mathrm{RRBN}+3 * \mathrm{RRSC})+(4 *(10-\mathrm{PA}))) / 10
$$

Donde:

RRBN: Recursos recreativos de base natural ( $\Sigma$ playas, balnearios, relieve, etc)

RRSC: Recursos recreativos socialmente construidos ( $\bar{x}$ de estética, centros deportivos, etc)

PA: Problemas ambientales ( $\Sigma$ de problemas ambientales)

Este Índice de Calidad Ambiental implica una propuesta, pero también un proceso abierto y participativo, dado que en su constitución coexisten variables objetivas y subjetivas. Para las objetivas se recurrió a fuentes estadísticas mientras que, para las subjetivas, la valoración es personal, basada en información de los sitios de los municipios, fotografías, videos, viajes a los lugares analizados y bibliografía. La Internet es, sin dudas, el principal medio que permite recabar datos para esta finalidad. De manera recíproca, la tabla con todas las variables se encuentra disponible online. ${ }^{5}$

Para plasmar la dimensión espacial del índice se utilizó el ArcGis 9.2 con el método de cortes naturales para delimitar los intervalos de los indicadores. Este es el método de clasificación por defecto del programa, que utiliza un algoritmo de optimización que da lugar a clases de valores similares, separados por puntos de interrupción. Es el recomendado para datos que no se distribuyen uniformemente y que no están muy sesgados hacia un extremo de la distribución.

\footnotetext{
${ }^{5}$ La tabla se encuentra disponible en www.cig.org.ar

Geo UERJ - Ano 14, no. 23, v. 1, $1^{\circ}$ semestre de 2012 p. 53-76

ISSN: 1415-7543 E-ISSN: 1981-9021

http://www.e-publicacoes.uerj.br/index.php/geouerj
} 


\section{Resultados}

Recursos recreativos de base natural

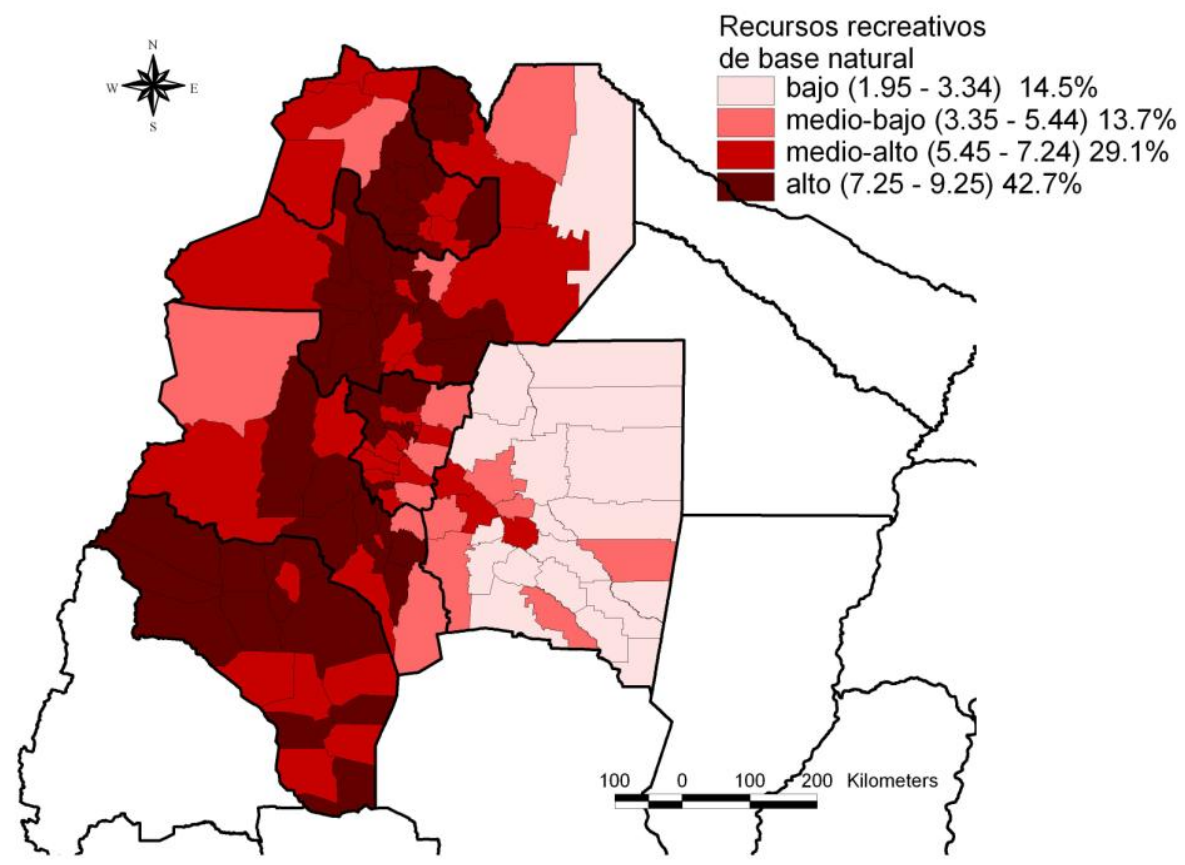

Mapa 2. Recursos recreativos de base natural. Región del NO Argentino.

Fuente: elaboración personal

En el mapa (Mapa 2) se destaca, en primer lugar, un conjunto de departamentos (42,7\% del total), que concentra la mayor presencia de estos recursos (7,25 a 9,25 puntos). Este numeroso grupo comprende: a) un corredor que se extiende desde el norte de Salta y Jujuy y coincide, en gran medida, con los oasis y las Sierras Subandinas, b) dos áreas de bolsones y Sierras en Catamarca y La Rioja y c) el extremo meridional de La Rioja, también en ámbito serrano. En estos tres casos se conjugan: imponente paisaje de ambientes montañosos, exuberante vegetación y fauna, diversos espejos de agua y, más puntualmente, centros termales y balnearios de gran belleza. El primer corredor coincide, además, con un área densamente poblada, que abarca varias capitales provinciales (Jujuy, Salta, Tucumán). Dentro de las áreas de sierras y bolsones la densidad de población resulta menor, aunque también se localizan dos capitales provinciales (Catamarca y La Rioja), ambas con menor importancia relativa en el sistema urbano regional. Por último, el sur riojano incluye tres departamentos con típico paisaje de las Sierras Pampeanas, muy atractivo en lo que respecta a recursos escénicos. 
Este primer conjunto -relativamente extenso, además de numeroso- es el que cuenta con los mejores recursos recreativos de base natural del NOA, lo que genera un entorno atractivo y diverso para el esparcimiento cotidiano de su población.

En segundo término, $42,8 \%$ de los departamentos del NOA, también posee recursos recreativos atractivos, pero estos no resultan tan significativos o se encuentran más alejados de la población residente alcanzando, por tanto, puntajes intermedios medio bajo y medio alto - (3,35 a 7,24 puntos). En este grupo tenemos: a) todos los departamentos situados en el ámbito puneño, b) los municipios del centro-este SaltoJujeño, c) casi todo el sur de Tucumán y su prolongación en Santiago y Catamarca y e) las sierras del sur de La Rioja.

En el caso de la Puna, la originalidad e inmensidad del paisaje se ve relativizada por las enormes distancias y la escasez de recursos hídricos, que dificultan a su población la posibilidad de disfrutar sus recursos escénicos; máxime por tratarse de un contexto donde predominan ampliamente las actividades económicas de subsistencia. El área centro-oriental de Salta y Jujuy posee recursos recreativos vinculados con sus espacios verdes y sus cursos y espejos de agua pero, la ausencia de relieve, la deja un escalón por debajo del primer grupo. Lo mismo ocurre con el sur de Tucumán. Finalmente, las sierras meridionales riojanas cuentan con recursos recreativos vinculados al relieve y, en menor medida, con sus recursos hídricos y vegetación (ambos relativamente más escasos).

Finalmente, el territorio más carente de recursos recreativos (1,95 a 3,34 puntos) reúne al 14,5\% de los departamentos y abarca dos grupos: a) este de Salta y b) la gran mayoría de Santiago del Estero. Ambos grupos se encuentran comprendidos en el "Chaco", subregión caracterizada en este sector por la virtual ausencia de relieve, difícil accesibilidad, relativa aridez, escasa cobertura vegetal, baja densidad demográfica y relativamente escasos recursos hídricos. Es por ello que en este grupo de departamentos -relativamente extensos y poco poblados- los atractivos "naturales" resultan particularmente escasos, predominando casi absolutamente la monotonía. 


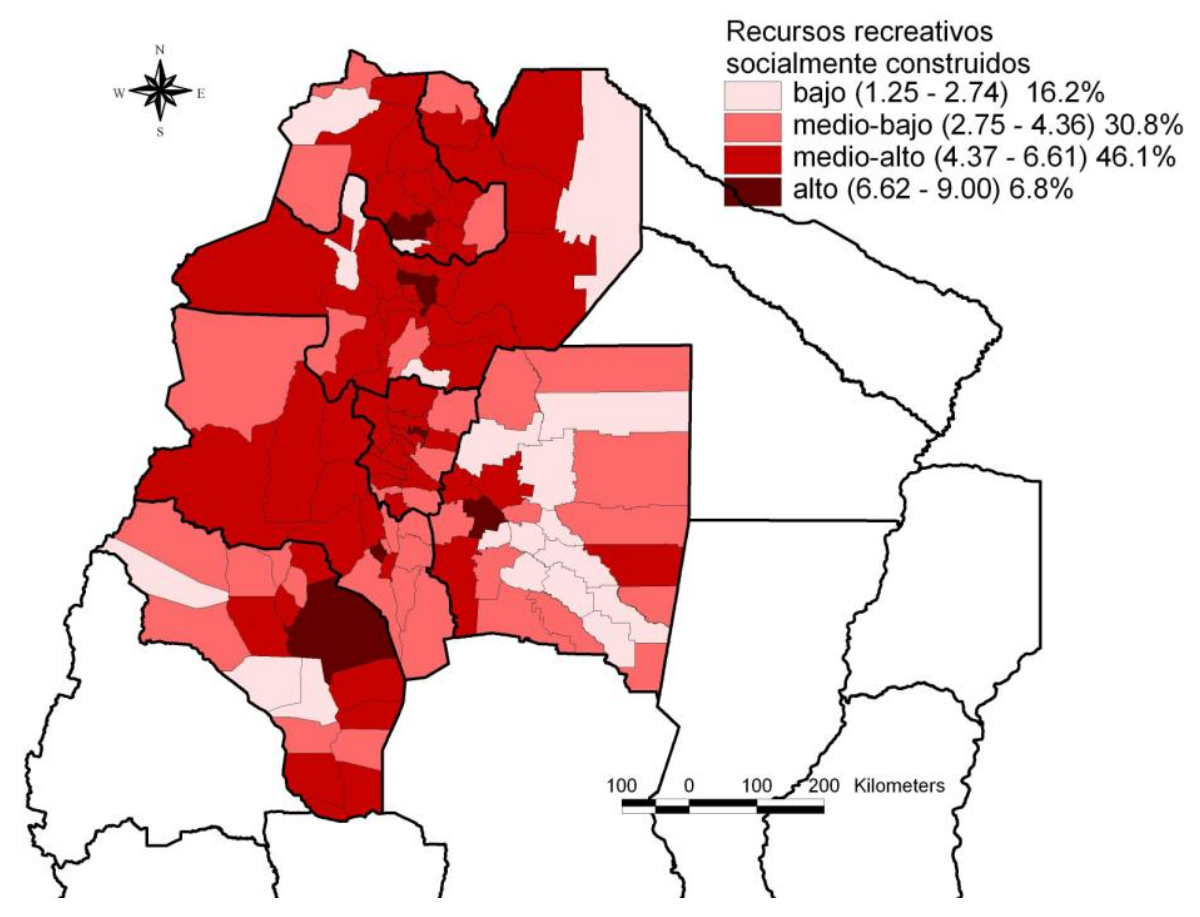

Mapa. 3. Recursos recreativos socialmente construidos. Región del NO Argentino.

Fuente: elaboración personal

El mapa (Mapa 3) exhibe la valoración de estos recursos en la Región del Noroeste Argentino. ${ }^{6}$ En primer lugar (6,62 a 9,00 puntos, tan sólo 6,8\% de los departamentos) se encuentran las áreas centrales de las seis capitales provinciales (Jujuy, Salta, Tucumán, Santiago del Estero, Catamarca y La Rioja) que, por su escala urbana y su primacía política, brindan servicios de especial jerarquía. Estos seis puntos constituyen los epicentros del esparcimiento regional, concentrando las principales actividades culturales, deportivas y comerciales de sus respectivas provincias.

En segundo término (4,37 a 6,61 puntos) se presenta un numeroso grupo de departamentos $(46,1 \%)$ que: a) rodean a los primeros, b) abarcan extensas áreas de Jujuy, Salta y Tucumán (excepto la Puna y el Chaco Salteño), c) comprenden el centro de Catamarca y varios departamentos Riojanos y d) unos pocos municipios de Santiago del Estero. En todos los casos se trata de departamentos encabezados por localidades menores a los 100.000 habitantes, que poseen razonable dotación de servicios

\footnotetext{
${ }^{6}$ Recordemos que en este caso los puntajes se otorgaron sobre la base del promedio de cada uno de los recursos recreativos socialmente construidos.

Geo UERJ - Ano 14, nº. 23, v. 1, $1^{\circ}$ semestre de 2012 p. 53-76

ISSN: 1415-7543 E-ISSN: 1981-9021

http://www.e-publicacoes.uerj.br/index.php/geouerj
} 
(educativos, sanitarios, comerciales), pero no grandes atractivos socialmente construidos para el esparcimiento cotidiano de su población.

Un tercer escalón (2,75 a 4,36 puntos) reúne al 30,8\% de los departamentos, bastante carentes aún en lo que respecta a amenidades socialmente construidas. Estos se encuentran espacialmente dispersos, más alejados de los atractivos, y sus cabeceras suelen ser pueblos grandes, por debajo de los 50.000 habitantes. Cuentan, tan sólo, con servicios (educativos, sanitarios, comerciales) básicos, siendo menos significativos aún los destinados a la recreación.

Finalmente, el grupo más desprovisto de estos recursos (1,25 a 2,74 puntos) incluye al $16,2 \%$ de los departamentos. En este último encontramos: a) los departamentos del chaco, (tanto salteño como santiagueño), y b) los municipios santiagueños situados al sur de la diagonal fluvial. En las restantes provincias del NOA este grupo tiene escasa presencia.

En todos los casos se trata de departamentos cuyas cabeceras las constituyen pueblos bastante pequeños, en donde reina la tranquilidad extrema. Se caracterizan, asimismo, por ser centros emisores de juventud y de aquellos segmentos poblacionales que presenten mayores inquietudes.

\section{Problemas ambientales}

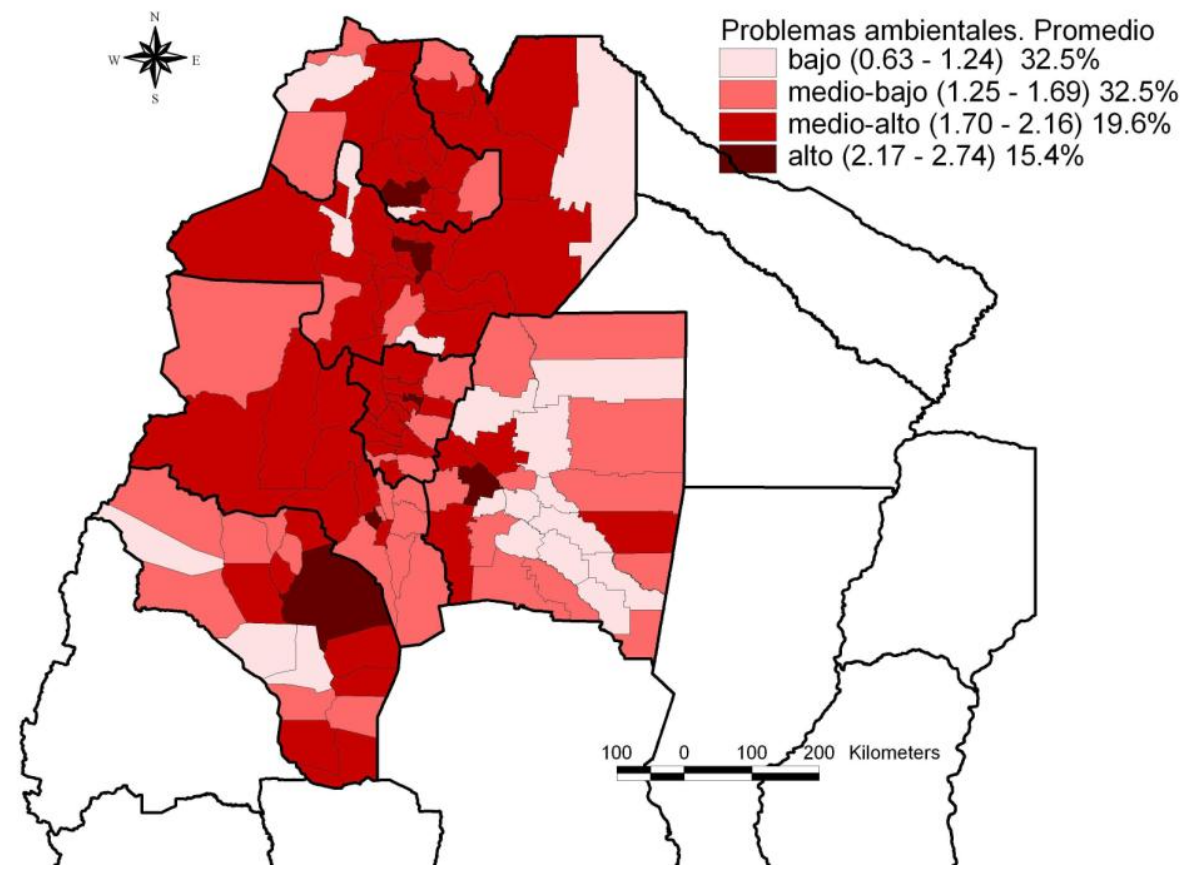

Mapa. 4. Costos ambientales. Promedio. Región del NO Argentino.

Geo UERJ - Ano 14, nº. 23, v. 1, $1^{\circ}$ semestre de 2012 p. 53-76

ISSN: 1415-7543 E-ISSN: 1981-9021

http://www.e-publicacoes.uerj.br/index.php/geouerj 
Fuente: elaboración personal

La Región del NOA padece costos ambientales de magnitud diversa. Para dimensionarlos hemos propuesto diversos grados de afectación (Mapa 4). Los mayores problemas (2,17 a 2,74 puntos) abarcan al $15,4 \%$ de los departamentos y se presentan en diversos sectores: a) oriente de Salta-Jujuy, b) en las Capitales provinciales de Salta, Tucumán, Santiago, Catamarca y sus alrededores. En el caso a) se combinan negativamente la tradicional lógica de "plantación" de los establecimientos azucareros jujeños ${ }^{7}$ con la expansión de cultivos transgénicos (particularmente soja). También resultan frecuentes los asentamientos precarios, presencia de basurales y los problemas de inundabilidad. Con respecto a los casos b) tenemos, como común denominador, la presencia de ciudades intermedias que concentran actividades industriales y sufren, en mayor medida, problemas de asentamientos espontáneos (lo que implica basurales, villas miseria, hechos delictivos, localizaciones con externalidades negativas). La mayor presencia de industrias trae consigo contaminación, ruido y congestionamiento propios de la mayor escala urbana. Esto es particularmente notorio en San Miguel de Tucumán en relación con la obsoleta agroindustria azucarera.

En un segundo escalón (1,70 a 2,16 puntos) se incluye al 19,6\% de los departamentos, en los cuales se presenta una combinación de situaciones: a) el sudeste de Salta-Jujuy, b) la puna Salteña, c) el sur tucumano y su prolongación en Santiago y Catamarca, d) las capitales de La Rioja y Jujuy y sus alrededores y e) tres departamentos santiagueños. En los casos a) y e) se trata de áreas de expansión sojera sobre montes nativos y pueblos originarios. En el caso b) se combinan: alto disconfort climático y alta tasa de hechos delictivos. ${ }^{8}$ En el caso c) tenemos asentamientos espontáneos, contaminación por plaguicidas e inundabilidad. Por último, en el caso d), los delitos afectan negativamente al caso jujeño y la presencia de basurales al riojano.

Finalmente, en los dos grupos con menores problemas (0,63 a 1,69 puntos) nos encontramos con numerosos departamentos (65\% del total) que, en general, carecen de agricultura transgénica, industrias obsoletas, mega-minería y de otras externalidades negativas, coexistiendo actividades agropecuarias de pequeña escala y de subsistencia con relativamente bajo impacto ambiental.

\footnotetext{
${ }^{7}$ Particularmente de Ingenio Ledesma.

${ }^{8}$ Esta última circunstancia nos parece difícil de explicar, salvo por el impacto del turismo vinculado con el "tren de las nubes" y el tránsito fronterizo.

Geo UERJ - Ano 14, nº. 23, v. 1, $1^{\circ}$ semestre de 2012 p. 53-76

ISSN: 1415-7543 E-ISSN: 1981-9021

http://www.e-publicacoes.uerj.br/index.php/geouerj
} 


\section{Índice de Calidad Ambiental}

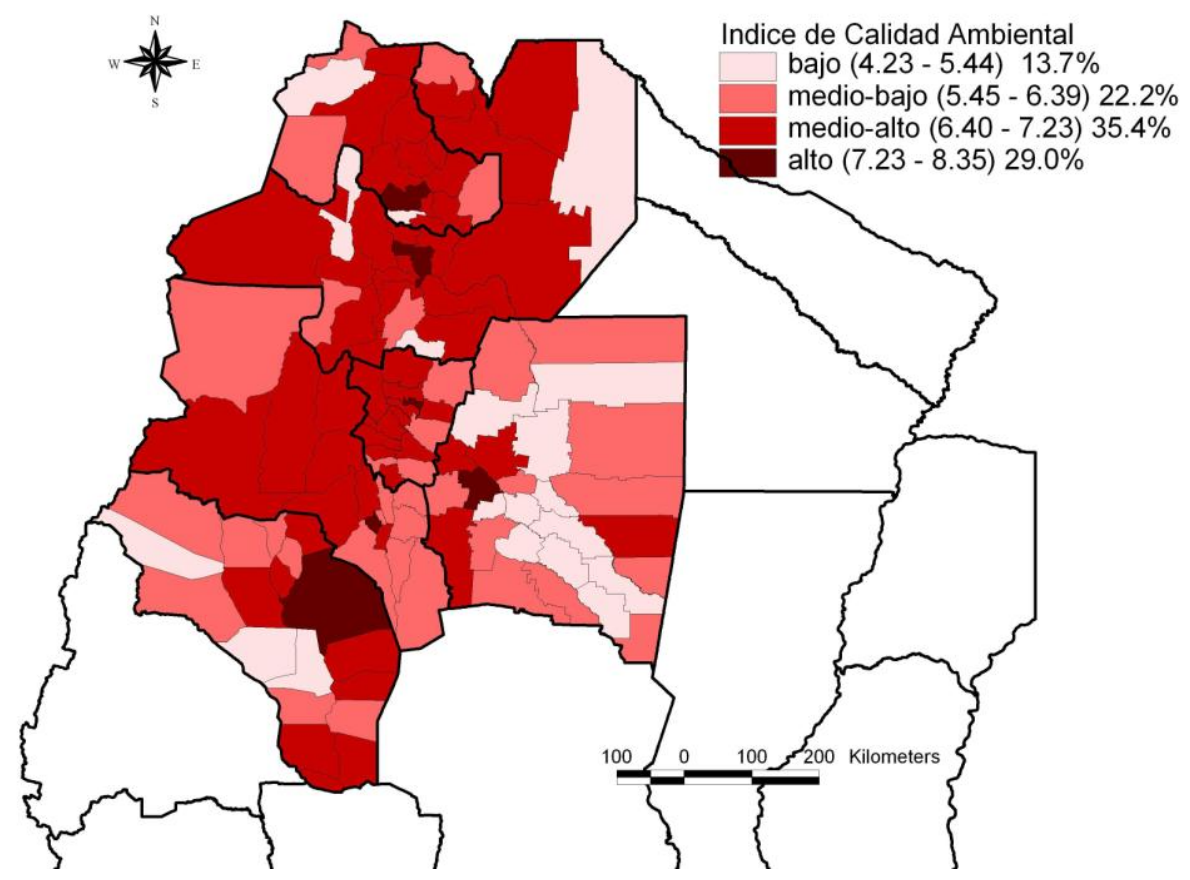

Mapa 5. Índice de Calidad Ambiental. Región del NO Argentino.

Fuente: elaboración personal

El mapa (Mapa 5) muestra que la mejor situación en lo que respecta a la calidad ambiental (7,23 a 8,35 puntos) se presenta en: a) un extenso corredor que incluye diversos departamentos de la Quebrada de Humahuaca y las sierras subandinas; b) cinco departamentos de Catamarca y c) seis departamentos de La Rioja. En el caso a) la magnificencia del paisaje se combina con una rica arquitectura de pueblos y culturas autóctonas. Además del relieve, la vegetación y la fauna, los numerosos cursos de agua brindan balnearios naturales y algunos centros termales. Los centros urbanos suelen disponer, asimismo, de servicios razonables en relación con la población residente. Los casos b) y c) se explican en virtud de los ámbitos de sierras pampeanas y precordillera, también sumamente pintorescos en lo que respecta a relieve y vegetación; en los cuales los oasis no sólo resultan productivos (agrícolas, ganaderos), sino también recreativos. Se destacan sus balnearios y algunos centros termales. Por otra parte la existencia de 
centros urbanos intermedios, con relativamente buena dotación de servicios e infraestructura, contribuye en el mismo sentido.

Las dos posiciones siguientes (5,45 a 7,23 puntos) predominan ampliamente (57,6\% de los departamentos). Se corresponden con sitios de atractivos intermedios (ya sea de base natural o socialmente construidos) y que también pueden padecen algunos problemas ambientales. Es la situación predominante en gran parte del territorio salteño, catamarqueño y riojano.

Finalmente, la peor situación relativa (4,23 a 5,44 puntos) se registra en los departamentos más carentes de recursos recreativos (tanto de base natural como socialmente construidos). Estos departamentos constituyen el 13,7\% del total y, en algunos casos, también pueden padecer algunos problemas ambientales, particularmente en relación con la deforestación y la expansión de la soja transgénica. Las peores situaciones se observan claramente en la gran mayoría de Santiago del Estero y el chaco salteño. En estos contextos la vida cotidiana, además de pobre desde el punto de vista material, suele resultar extremadamente monótona, constituyendo una invitación a la resignación o a la emigración. La Tabla 2 exhibe a modo de resumen la cantidad de departamentos para cada dimensión del ICA y su respectiva puntuación (valoración):

Tabla 2. Cantidad de departamentos según dimensión y puntuación

\begin{tabular}{|l|l|l|l|l|}
\hline Puntuación & $\begin{array}{l}\text { Recursos } \\
\text { recreativos de } \\
\text { base natural }\end{array}$ & $\begin{array}{l}\text { Recursos } \\
\text { socialmente } \\
\text { construidos }\end{array}$ & $\begin{array}{l}\text { Problemas } \\
\text { ambientales }\end{array}$ & $\begin{array}{l}\text { Índice de } \\
\text { Calidad } \\
\text { Ambiental }\end{array}$ \\
\hline Bajo & $17(14,5 \%)$ & $19(16,2 \%)$ & $18(15,4 \%)$ & $16(13,7 \%)$ \\
\hline Medio-bajo & $16(13,7 \%)$ & $36(30,8 \%)$ & $23(19,6 \%)$ & $26(22,2 \%)$ \\
\hline Medio-alto & $34(29,1 \%)$ & $54(46,1 \%)$ & $38(32,5 \%)$ & $41(35,4 \%)$ \\
\hline Alto & $50(42,7 \%)$ & $8(6,8 \%)$ & $38(32,5 \%)$ & $34(29,0 \%)$ \\
\hline
\end{tabular}

\section{Conclusiones}

Un índice de calidad ambiental que intente ser completo necesita recurrir no solo a las habituales variables vinculadas con el medio físico-natural sino también al espacio construido donde la población desarrolla su quehacer cotidiano. Consiguientemente la presente publicación se propuso elaborar un índice de calidad ambiental (ICA) que contenga ambas dimensiones para luego aplicarlo a los departamentos que componen el Noroeste de la República Argentina. En su elaboración se recurre a fuentes de variado origen en la que se combinan tanto las ponderaciones objetivas como las subjetivas. 
Los recursos recreativos socialmente construidos están relacionados con el componente demográfico ya que se corresponden con las zonas más pobladas y muy particularmente donde habitan los sectores con mayor capacidad de demanda y consumo. En general, el acceso a las instalaciones vinculadas a la cultura o al deporte es pago por lo que su ubicación espacial coincide con el emplazamiento de los sectores sociales con mayor poder adquisitivo. Esto es visible en las seis capitales provinciales, pero fundamentalmente en el Gran San Miguel de Tucumán.

Respecto de los recursos recreativos de base natural, su distribución y apropiación también registra un componente de diferenciación espacial. Como ya se refiere en el párrafo anterior, a escala intra-departamental los grupos de mayores ingresos también poseen mejor acceso al sectores naturalmente atractivos, al a vez que externalizan los costos del "desarrollo" al resto de la sociedad.

Los resultados obtenidos muestran que sólo $29 \%$ de los departamentos del NOA exhibe las mejores condiciones ambientales. Este grupo comprende: a) un extenso corredor que incluye diversos departamentos de la Quebrada de Humahuaca y las sierras subandinas; b) cinco departamentos de Catamarca y c) seis departamentos de La Rioja.

La peor situación relativa (4,23 a 5,42 puntos) se registra en los departamentos más carentes de recursos recreativos (tanto de base natural como socialmente construidos). Estos departamentos constituyen el 13,3\% del total y, en algunos casos, también pueden padecer algunos problemas ambientales, particularmente en relación con la deforestación y la expansión de la soja transgénica. En estos contextos la vida cotidiana, además de pobre desde el punto de vista material, suele resultar extremadamente monótona constituyendo, como ya señalamos, una invitación a la resignación o a la emigración.

Entre estos dos extremos se sitúan la mayoría de los departamentos, que cuentan con sitios de atractivos intermedios (ya sea de base natural o socialmente construidos) y que también pueden padecen algunos problemas ambientales.

La elaboración del índice con su correspondiente cartografía constituye un aporte para la sistematización, medición y síntesis del proceso de diferenciación espacial socio-ambiental presente en la República Argentina. En este sentido se espera que su futura implementación en la totalidad del territorio nacional no quede circunscripta exclusivamente al ámbito científico y académico, sino que también sea 
una variable original y dinámica, en constante transformación y reevaluación para la adecuada gestión del territorio.

\section{Bibliografía}

APARICIO Francisco; DIFRIERI Horacio. La Argentina. Suma de Geografía. Buenos Aires: Peuser. 1958-1963.

ARAÑA, Jorge; LEÓN, Carmelo y GONZÁLEZ, Matías. Valoración múltiple de bienes públicos urbanos mediante técnicas de preferencias declaradas. En: Hacienda pública y convergencia europea. X Encuentro de Economía Pública, Santa Cruz de Tenerife: España, 2003. p. 1-16.

BOLSI, Alfredo. Población y territorio del Noroeste argentino durante el siglo XX. Revista Geográfica, México, n. 135, p. 137-161. 2004.

BOLSI, Alfredo; MADARIAGA, Horacio; PAOLASSO, Pablo. La calidad de vida de la población en el Noroeste Argentino. En: AUTOR Guillermo (ed.) Geografía y Bienestar. Situación local, regional y global de la Argentina luego del Censo de 2001. Buenos Aires: EUDEBA. 2008, 556 p. p. 263-298.

BOLSI, Alfredo; PAOLASSO, Pablo. Geografía de la pobreza en el Norte Grande Argentino. San Miguel de Tucumán: ISES, PNUD, 2008. 296 p.

BORONI, Gustavo; GÓMEZ LENDE, Sebastián y AUTOR, Guillermo. Geografía, calidad de vida y entropía. Aportes de la teoría de la información para la construcción de un índice de calidad de vida a escala departamental (1991-2001). En: AUTOR, Guillermo y GÓMEZ LENDE, Sebastián (autores/comp.) Desigualdad y Calidad de Vida en la Argentina (1991-2001). Aportes empíricos y metodológicos. Tandil: Editorial REUN, 2005. 381 p. p. 63-86.

AUTOR, Juan; AUTOR, Guillermo. Propuesta y aplicación de un índice de calidad ambiental para la Ciudad y Provincia de Buenos Aires (Argentina). Journal of Latin American Geography, Texas, vol. 10, n.1, p. 69-82. 2011.

CEPEDA, Rosana; MARINELLI, Claudia; GÓMEZ LENDE, Sebastián y AUTOR, Guillermo. Técnicas de análisis multivariado para la determinación de calidad de vida. En: MEMORIAS DEL PRIMER SEMINARIO ARGENTINO DE GEOGRAFÍA CUANTITATIVA. Buenos Aires. GEPAMA-FADU-UBA, 2004. p.1-16. 
CHIOZZA, Elena. (Director) El país de los argentinos. Buenos Aires: Centro Editor de América Latina, 1987. 382 p.

CHIOZZA, Elena; Iglesias Alicia. Atlas total de la República Argentina. Buenos Aires: Centro Editor de América Latina, 1983.

DAUS, Federico. Fundamentos para una división regional de la Argentina. Buenos Aires: Instituto de Geografía - UBA, 1969. 36 p.

DEFENSORÍA DEL PUEBLO DE LA NACIÓN. Atlas del Riesgo ambiental de la niñez de la Argentina. Disponible en http://defensoresymedios.org.ar/wpcontent/uploads/2010/04/Atlas.pdf Acceso en septiembre 2010.

DIFRIERI, Horacio. Las regiones naturales. En: APARICIO F; DIFRIERI, H. La Argentina, suma de geografía. Buenos Aires: Peuser, 1958-1963. p. 351-471.

DIRECCIÓN NACIONAL DE POLÍTICA CRIMINAL. Estadísticas en Materia de Criminalidad. Ministerio de Justicia, Seguridad y Derechos Humanos. Presidencia de la Nación. Disponible en: http://www.jus.gov.ar/areas-tematicas/estadisticas-enmateria-de-criminalidad.aspx Acceso en marzo 2011.

ESCOBAR, Luis. Indicadores sintéticos de calidad ambiental: un modelo general para grandes zonas urbanas. Eure, Santiago de Chile, vol. 32 n.96, p.73-98. 2006.

FERNÁNDEZ, Roberto. La ciudad verde: teoría de la gestión ambiental urbana. Buenos Aires: Espacio Editorial, 2000. 517 p.

FRENGUELLI, Joaquín. Las grandes unidades físicas del territorio argentino. GAEA, Buenos Aires, vol. 3, p. 5-114. 1946.

GEOSISTEMAS. Mapa de riesgos naturales en la Argentina. Buenos Aires: Geosistemas, 1997.

GÓMEZ LENDE, Sebastián; AUTOR, Guillermo. Población y calidad de vida en la Argentina (1991-2001). La fragmentación de la sociedad y el territorio. En: AUTOR, Guillermo, GÓMEZ LENDE, Sebastián (autores/comp.) Desigualdad y Calidad de Vida en la Argentina (1991-2001). Aportes empíricos y metodológicos. Tandil: Editorial REUN, 2005. 381 p. p. 199-240.

HERZER, Hilda; GUREVICH, Raquel. Degradación y desastres: parecidos y diferentes. Tres casos para pensar $y$ algunas dudas para plantear. En: 
FERNÁNDEZ, María (comp.) Ciudades en riesgo. Lima: La Red-Usaid. 2006. 140 p. p. $75-91$.

INSTITUTO NACIONAL DE ESTADÍSITICAS Y CENSOS. PBG por provincia y sector de actividad económica. Buenos Aires.

INSTITUTO NACIONAL DE ESTADÍSITICAS Y CENSOS Censo nacional de población, hogares y vivienda 2001. Disponible en Censo Nacional de población, hogares y vivienda, 2001. http:// www.indec.gov.ar/ Acceso en agosto 2007.

IRAM. Clasificación bioambiental de la República Argentina. Buenos Aires: Instituto Argentino de normalización, 1996.

KUHN, Franz. Fundamentos de fisiografía argentina. Buenos Aires: Biblioteca del Oficial, 1922. $215 \mathrm{p}$.

LORENZINI, Horacio; REY BALMACEDA, Raúl. Geografía de la Argentina. Buenos Aires: AZ Editora, 1999. 284 p.

LUENGO, Gerardo. Elementos para la definición y evaluación de la calidad ambiental urbana. Una propuesta teórico-metodológica. En: IV SEMINARIO LATINOAMERICANO DE CALIDAD DE VIDA URBANA. Tandil: Universidad Nacional del Centro, 1998. p. 1-8.

MARINELLI, Claudia.; TORCIDA, Sebastián; CEPEDA, Rosana; GARCÍA, María y AUTOR, Guillermo. Un procedimiento alternativo para la selección estadística de variables de calidad de vida. En: AUTOR, Guillermo y GARCÍA, María (autores/comp.) Calidad de Vida Urbana: aportes para su estudio en Latinoamérica, pp. Tandil: Centro de Investigaciones Geográficas - UNCPBA. 1999. 299 p. p. 133-142.

MCCANN, Eugene. 'Best Places': Interurban Competition, Quality of Life and Popular Media Discourse. Urban Studies, California, vol. 41, n.10, p. 1909-1929. 2004.

METZGER, Pascale Medio ambiente urbano y riesgos: elementos de reflexión. En: Fernández M (comp.) Ciudades en riesgo. Ciudades en riesgo. Lima: La Red-Usaid. 2006. 140 p. p. $43-56$.

RAMÍREZ, Liliana. El método de jerarquías analíticas de Saaty en la ponderación de variables. Aplicación al nivel de mortalidad y morbilidad en la provincia del Chaco. Comunicaciones científicas y tecnológicas de la Universidad Nacional del Nordeste, Resistencia: UNNE, 1-14. 2004.

Geo UERJ - Ano 14, no. 23, v. 1, $1^{\circ}$ semestre de 2012 p. 53-76 ISSN: 1415-7543 E-ISSN: 1981-9021

http://www.e-publicacoes.uerj.br/index.php/geouerj 
ROGERSON, Robert. Quality of Life and City Competitiveness. Urban Studies, California, vol. 36, n. 5-6, p. 969-985. 1999.

ROHMEDER, Wilhelm. Argentinien; eine landeskundliche Einführung. Buenos Aires: Beutelspacher, 1943. 320 p.

SANTOS, Milton. A Natureza do Espaço. Técnica e tempo. Razâo e emoçâo. Hucitec: Sâo Paulo, 1996. 384 p.

SIRAGUSA, Alfredo (1958) República Argentina: Regiones geográficas. Buenos Aires (mimeo).

STERIMBERG, Edith; SANCHEZ, Carlos; CUERVO DE FORERO, Adriana, y RAMÍREZ, Juan. Diseño de un sistema de indicadores socioambientales para el distrito capital de Bogotá. Serie estudios y perspectivas. Santiago de Chile: CEPALNaciones Unidas, 2004.

TANGUAY, Georges; RAJAONSON, Juste; LEFEBVRE, Jean y LANOIE, Paul. 2010. Measuring the sustainability of cities: A survey-based analysis of the Use of Local Indicators, Ecological Indicators, vol. 10, n.2, Oxford, p. 407-418. 2010.

VALPREDA, Claudia. Sistema de Información Geográfica (SIG)-teledetección y evaluación multicriterio (EMC) en un estudio de evaluación de impacto ambiental (EIA). En: Memorias XI Conferencia Iberoamericana de Sistemas de Información Geográfica. Luján: Argentina, 2007. p. 1-23.

VAN KAMP, Irene; LEIDELMEIJER, Kees; MARSMANA, Gooitske and DE HOLLANDER, Augustinus. Urban environmental quality and human well-being. Towards a conceptual framework and demarcation of concepts; a literature study. Landscape and Urban Planning, Oxford, vol.65, p. 5-18. 2003.

AUTOR, Guillermo. Geografía y Bienestar. Situación local, regional y global de la Argentina luego del Censo de 2001. Buenos Aires: EUDEBA, 2008. 556 p.

AUTOR, Guillermo. Environmental risks, demographic dynamic and Life Quality. Argentina at beginning of XXI century. Acta Universitatis Carolinae-Geographica, Praga, vol. 2, p. 115-134, 2010.

AUTOR, Guillermo. Geografía y bienestar en la Argentina. La desigualdad regional a comienzos del XXI. En: TORRADO, Susana (ed.) El costo social del ajuste (Argentina, 1976-2002) (Tomo II). Buenos Aires: Edhasa, 2010. 376 p. p. 335-357. 
AUTOR, Guillermo; AUTOR, Juan. Aplicación de un índice de calidad ambiental a

la Región Pampeana Argentina. Finisterra, Lisboa, vol. XLVI, n. 91, p. 49-68. 2011.

Artigo encaminhado para publicação em julho de 2012.

Artigo aceito para publicação em julho de 2012. 